\title{
Cidofovir Anhydrous
}

National Cancer Institute

\section{Source}

National Cancer Institute. Cidofovir Anhydrous. NCI Thesaurus. Code C77925.

An anhydrous form of cidofovir, a synthetic, acyclic monophosphate nucleotide analog of deoxycytidine with antiviral activity, mostly used against cytomegalovirus (CMV). After incorporation into the host cell, cidofovir is phosphorylated by pyruvate kinases to its active metabolite cidofovir diphosphate. Cidofovir diphosphate, bearing structural similarity to nucleotides, competes with deoxycytosine-5-triphosphate (dCTP) for viral DNA polymerase and gets incorporated into the growing viral DNA strands. As a result, it prevents further DNA polymerization and disrupts DNA replication of viruses. 